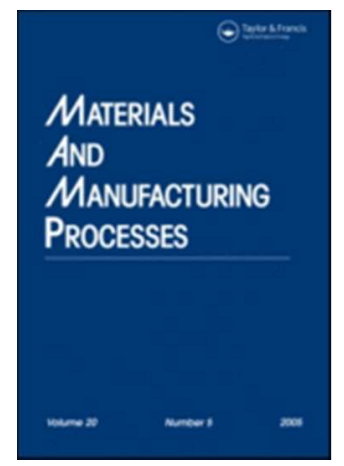

\title{
Electrode Surface Treatments In Sludge Electro-Osmosis Dewatering
}

\begin{tabular}{|c|c|}
\hline Journal: & Materials and Manufacturing Processes \\
\hline Manuscript ID & LMMP-2016-1053.R2 \\
\hline Manuscript Type: & Original Article \\
\hline Date Submitted by the Author: & $\mathrm{n} / \mathrm{a}$ \\
\hline Complete List of Authors: & $\begin{array}{l}\text { Gronchi, Paolo; Politecnico di Milano, Chemistry, Materials and Chemical } \\
\text { Engineering } \\
\text { VISIGALLI, SIMONE; Politecnico di Milano Dipartimento di Chimica Materiali } \\
\text { e Ingegneria Chimica Giulio Natta, } \\
\text { CANZIANI, ROBERTO; Politecnico di Milano, } \\
\text { Brenna, Andrea; Politecnico di Milano, Dipartimento di Chimica, Materiali e } \\
\text { Ingegneria Chimica "Giulio Natta" } \\
\text { COLOMINAS, CARLES; Flubetech S.L, } \\
\text { MONTALà, FRANCESC; FLUBETECH S.L., } \\
\text { COT, VICTOR; FLUBETECH S.L., } \\
\text { STRADI, ARISTIDE; AST System Automation, } \\
\text { FERRARI, GIANCARLO; AST System Automation, } \\
\text { JIMENEZ, CRISTINA; AIN - Asociación de la Industria de Navarra, } \\
\text { FUENTES, GONZALO; AIN - Asociación de la Industria de Navarra, } \\
\text { Georgiadis, Argyrios; AIN - Asociación de la Industria de Navarra, }\end{array}$ \\
\hline Keywords: & $\begin{array}{l}\text { corrosion, coatings, electrophoresis, osmosis, cathodic, biomass, erosion, } \\
\text { morphology }\end{array}$ \\
\hline
\end{tabular}

\section{SCHOLARONE ${ }^{m}$ \\ Manuscripts}


ELECTRODE SURFACE TREATMENTS IN SLUDGE ELECTROOSMOSIS DEWATERING

\author{
Paolo Gronchi ${ }^{1}{ }^{*}$, Roberto Canziani ${ }^{2}$, Andrea Brenna $^{1}$, Simone Visigalli $^{2}$, \\ Carles Colominas ${ }^{3}$, Francesc Montalà ${ }^{3}$, Victor $\mathrm{Cot}^{3}$, Aristide Stradi ${ }^{4}$, Giancarlo Ferrari ${ }^{4}$, \\ Cristina Diaz ${ }^{5}$, Gonzalo Garcia Fuentes ${ }^{5}$, Argyrios Georgiadis ${ }^{5}$ \\ ${ }^{1}$ Department of Chemistry, Materials and Chemical Engineering, Politecnico di Milano, Milano, Italy \\ ${ }^{2}$ Department of Civil and Environmental Engineering, Politecnico di Milano, Milano, Italy \\ ${ }^{3}$ Flubetech S.L., Barcelona, Spain \\ ${ }^{4}$ AST System Automation S.A.S., Modena, Italy \\ ${ }^{5}$ AIN-Asociación de la Industria Navarra, Cordovilla, Spain \\ * Corresponding author. \\ Tel.: +39-02-23993274. \\ E-mail address: paolo.gronchi@polimi.it
}

\begin{abstract}
The sewage sludge dewatering produced by Wastewater Treatment Plants is a multifaceted process due to the presence of colloid fractions. Electro-osmosis could be a suitable technique to reduce the water content of the final sludge. Electric fields of $10 \mathrm{~V} / \mathrm{cm}, 15 \mathrm{~V} / \mathrm{cm}$ and $20 \mathrm{~V} / \mathrm{cm}$ have been studied for electro-osmosis tests under the pressure of a static or rotating piston, obtaining a dry solids content up to $40-45 \%$, with respect to $25-30 \%$ obtained by mechanical methods. In order to optimise the process, the corrosion behaviour and the wear of the anodic material appear the main critical aspects, due to the high circulating current density and the use of a rotating electrode. We compared the efficiency and the corrosion resistance of dimensionally stable anodes (DSA) with respect to bare stainless steel (AISI 304) and stainless steel coated by PVD technique with TiN, AlTiN and DLC. Characterization of the anode surfaces by SEM and potentiodynamic tests, show that DSA is the most suitable material for our application. However, efficiencies of the electro-osmosis processes have been found comparable, in terms of developed current densities and total energy consumptions, for short-test duration.
\end{abstract}

Keywords: electro-osmosis; dewatering; sludge; DSA; anode; corrosion. 


\section{Introduction}

The so-called "activated sludge process" is adopted by almost the totality of urban and industrial wastewater treatment plants to achieve the concentration limits of biodegradable pollutants stated by the law to allow the discharge of treated effluents to natural water bodies (rivers, lakes and the sea). About half of the organic pollution load treated by the activated sludge process is oxidised and converted into water and carbon dioxide, while the remaining is converted into biomass, called "excess biological sludge" or "waste sludge". After reducing both the content of biodegradable matter and the water content through mechanical dewatering or thermal drying, the sludge becomes a product suitable for its final disposal.

When compared with thermal (evaporative) processes for water reduction, mechanical dewatering is often selected due to its low energy requirement. The processes of mechanical dewatering are largely developed on the industrial scale and can produce sludge with $20-25 \%$ of dry solid (DS) content and, in some cases, up to $30 \%$. However, the high DS values demanded for thermal valorisation of sludge cannot be achieved by mechanical dewatering techniques.

Seeking new and efficient methods for dewatering, Yoshida [1], Barton et al. [2], Gingerich et al. [3] exploited electro-osmosis in order to remove water from sludge: the application of an electric field, sometimes in combination with pressure, seems capable to increase the DS content well beyond the values that can be achieved by mechanical means [4]. Among electrokinetic phenomena, electro-osmosis rules this process and leads to a transport of water molecules to the negative electrode (cathode), increasing the dry matter significantly and lowering the energy consumption with respect to conventional techniques.

The application of an electric field, combined with a pressure, tends to increase sludge dewaterability: electro-osmosis reduces the interstitial water and some extent of the vicinal water, thus resulting in a dryer sludge cake [5].

Many experimental factors can influence the reduction of water content and, consequently, the process yield. The critical processing factors are voltage (or current), pressure, time, zeta potential, conditioning parameters, polyelectrolyte characteristics, temperature etc. $[6,7]$ The electrode reactions are affected not only by the materials of the electrode but also by the ions in the electrolyte: they may cause some hindering during electro dewatering. Reactions at the cathode produce hydroxide ions and those at the anode produce protons and this may result in a $\mathrm{pH}$ gradient across the filter cake [1, 5, 8]. Citeau [8], Yuan [9], and Tuan et al. [10] reported that the $\mathrm{pH}$ drop relates to the reduction of the absolute value of the zeta potential, thus the decrease in $\mathrm{pH}$ (specifically at the anode) reduced the electro-osmotic flow during direct current application $[1,5,8,11]$.

The oxidation of the anode material, due to oxygen evolution, ohmic heating and $\mathrm{pH}$ decrease, reduces the process efficiency [12] and can cause in some applications the contamination of the filter cake or filtrate, increasing the operating cost. Anodes such as stainless steel will be subject to 
corrosion, thus the use of dimensionally stable anode (DSA) materials is necessary [12]. The anodes used in electro-osmosis experiments are usually made of conventional metallic plates (or meshes) such as stainless steel or nickel steel (which have sufficient strength but are easily corroded), graphite (which is cheap but fragile and cannot undergo to pressure conditions) and copper. Raats et al. [13] and Saveyn et al. [14] documented that the use of titanium plates coated with mixed metal oxide (MMO), such as $\mathrm{Ir}_{2} \mathrm{O}_{3}$ or $\mathrm{RuO}_{2}$, prevents corrosion: these conducting ceramic materials seem to be highly effective due to their excellent strength, flexibility and corrosion resistance. On the contrary, the choice of the materials for the cathode presents less problems in terms of corrosion resistance: stainless steel, copper and nickel plates or meshes can be used [15].

In this paper a preliminary investigation of materials to be used as anodes in the process of sludge electro-dewatering is carried out. The anode metal is subject to corrosion and wear due to the low $\mathrm{pH}$ of the sludge as the current moves through the cake, oxygen evolution, high organic content, and compacting/rotation of the piston. Dimensionally stable anodes are strongly resistive in this kind of environment. Our aim has been the study of stainless steel AISI 304 as anode in the electroosmosis process. We compared performances, efficiencies and corrosion resistance with respect to titanium MMO. We also evaluated the behaviour of PVD coating on the metal under the same conditions. Characterization of the anodes samples by SEM and potentiodynamic tests were used to express the corrosion resistance of the materials.

\section{Materials and methods}

Sludge samples were taken from San Rocco (Milan) WWTP. We used aerobically digested sludge, pre- dewatered by mechanical treatment with two different devices: the first samples are taken after the Bucher (Bucher Unipektin) treatment, the other ones after filter press. Each sludge sample dewatered by filter press was crumbled and homogenised by a shredder (Moulinex - La Moulinette), which leads to a uniform cake to be treated. In order to control the sludge quality, the electrical conductivity was measured by a conductivity meter (B\&C Electronics - C 125.2) and $\mathrm{pH}$ by a $\mathrm{pH}-\mathrm{meter}$ (Metrohm 827 pH Lab).

Sludge samples were stored at $4{ }^{\circ} \mathrm{C}$ for less than five days prior to the experiments in order to keep constant their properties ( $\mathrm{pH}$ and conductivity) and hinder the possibility of degradation. All types of sludge used for our electro-osmosis tests are shown in Table 1.

The lab-scale device used for sludge electro-osmosis dewatering is described in Figure 1. It consists of: a) cylindrical glass vessel ( $\mathrm{h}=176 \mathrm{~mm}, \varnothing=80 \mathrm{~mm})$; b) cooling water-jacket; c) compressed air system (1-4.5 bar); d) double effect cylinder (200 mm stroke) SMC-CP96 (piston); e) DC power supply (30 V- 5 A), f) anode: DSA Ti-MMO or stainless steel discs; g) cathode: stainless steel mesh (AISI 304); e) cloth: PTT (polytrimethylene terephthalate).

The upper electrode (the anode) is attached to the piston, while the lower stainless steel mesh cathode (AISI 304) is covered by the PTT filter medium. The cathode and the anode are connected to the 
negative and the positive pole of the DC power supply (GBC bench scale generator, maximum $30 \mathrm{~V} / 5 \mathrm{~A}$ ) respectively. The piston is connected to the laboratory pressurisation system, with pressure regulation.

The water is then collected in a graduated cylinder in order to measure the weight of the liquid lost during the experiments with respect to time and calculate the sludge dewatering rate. In order to control temperature during dewatering tests, a thermocouple (Data logger thermometer OMEGAHH306A) is inserted into the glass cell.

The rotation of the piston used for static experiments is obtained by bevel gears, which transmit the movement of a mechanical stirrer.

The electro-dewatering tests procedure was similar to that used by Mahmoud et al. [6] and consists of two successive stages:

a) filtration/compression under pressure $(5 \mathrm{~min})$;

b) application of the electric field at the selected operating voltage, keeping the applied pressure constant.

The end time of the dewatering test is taken when no more than two drops of filtrate are collected in 5 min.

Initially the glass cell is filled with homogenized sludge: $1 \mathrm{~cm}$ of cake thickness, corresponding to $35-45 \mathrm{~g}$ of sludge depending on the initial DS amount, is used for static piston experiments. Then it is closed by the cover and the piston starts applying pressure. Sludge is pressed between the upper anode (on the PTFE support) and the lower PTT filter cloth (placed on the cathode mesh). During the initial 5 min of pressure application no water is extracted during the application of pressure as the sludge has been already mechanically dewatered. Then, electric field is switched on, and values of currents in function of time are recorded. At the same time, every minute the weight of extracted water and cell temperature are registered. When the interval between two drops of water exceeds two minutes, the experiment is stopped. At the end of the experiment: the dewatered cake is released and weighted. Its DS amount is determined by drying at $105^{\circ} \mathrm{C}$ [16]. Each experiment is repeated three times.

When the dynamic piston is used, rotation is started after 7 minutes of electric field application and a higher sludge thickness $(3 \mathrm{~cm})$ is investigated.

We evaluated the electro-dewatering parameters on the basis of the following assumptions:

- At low electric field values, the increase of the applied pressure (up to $600 \mathrm{kPa}$ ) has a strong effect on the dewatering process and leads to the enhancement of the kinetics. We choose 3 bar of pressure as an intermediate value of those studied in previous works [4].

- The amount of initial DS (and consequently cake thickness) affects the electrical resistance of the cake especially at the first stages of the electro-dewatering process [17]. In order to avoid a strong increase of the electrical resistance, the cake thickness value was fixed at $1 \mathrm{~cm}$ for static experiments. 
- The temperature at the anode increases with the applied potential due to ohmic heating. Potentials higher than $50 \mathrm{~V}$ could increase anode temperature over $90^{\circ} \mathrm{C}$ [6], with deleterious effect on the electrode's materials. We choose to keep potential in the range 10-15-20 V.

- The aim of the dynamic piston is the dryness homogenisation in the sludge cake and the neutralization of the $\mathrm{pH}$ gradient developed with electrodes reactions. A low speed (10 rpm) was sufficient for our objectives.

As for electrode materials, DSA (Industrie De Nora SpA, Milan, Italy) consist of a titanium matrix coated by iridium dioxide with elements like cobalt, iron, platinum, neodymium, manganese and nickel. Electrodes made by AISI 304 stainless steel, which has the best quality/price ratio for our applications were then tested for economic reasons. Indeed, the cost of stainless steel is around 5-7 times that of carbon steel, whereas titanium MMO electrodes have a cost around 50-100 times higher depending on the iridium and ruthenium oxide content. The coatings applied on steel were TiN, AlTiN, DLC (diamond like carbon), which are usually exploited for their wear and abrasion resistance. In Table 2 the coatings properties are reported. On the materials characterisation, Figure 2 shows the cyclic potentiodynamic tests (scan rate $0.17 \mathrm{mV} / \mathrm{s}$ ) on X5CrNi18-10 (AISI 304) and TiMMO (DSA mesh electrode) before electro-osmosis tests. Aerobically digested sludge has been used as electrolytic solution in order to simulate the conditions of electro-dewatering tests.

The curves concerning the AISI 304 electrode show that the free corrosion potential $\left(\mathrm{E}_{\text {corr }}\right)$ is -0.339 $\mathrm{V} \mathrm{Ag} / \mathrm{AgCl} \mathrm{KCl}_{\mathrm{Kat}}$ while, corresponding to $-0.170 \mathrm{~V} \mathrm{Ag} / \mathrm{AgCl}_{\mathrm{KCl} \text {,sat }}$ (potential passive range), an increase of the curve slope is observed: the current increases slowly for each potential variation due to high anodic resistance of the passive metal. Oxygen evolution reaction and passive film breakdown is close to $1 \mathrm{~V} \mathrm{Ag} / \mathrm{AgCl}_{\mathrm{KCl} \text {,sat. }}$ The free corrosion potential of the DSA is between 0 and $-0.2 \mathrm{~V}$ $\mathrm{Ag} / \mathrm{AgCl}_{\mathrm{KCl} \text {,sat. }}$. Potentiodynamic tests on the two electrodes differ strongly in the decreasing potential curve (reverse scan). While in the case of AISI 304 the curves at increasing polarization and at decreasing polarization (reverse scan) do not coincide, in the case of Ti-MMO the curves coincide. The meaning of this behaviour is related to the absence of modification of the passive film on the Ti-MMO electrode during trans-passivity. In case of stainless steel, the passivity is destroyed by acidity formed by oxygen evolution reaction and corrosion occurs at strong penetration rate. In case of activated titanium, the mixed metal oxides on the surface are able to resist to the acidity at $10 \mathrm{~A} / \mathrm{m}^{2}$, without any corrosion of the metal.

\section{Results and discussion}

Our aim in performing our experiments has been the choice of suitable values of pressure, electric field and sludge cake thickness in order to obtain the highest efficiency and the best results in terms of final DS amount.

After preliminary tests, we set the initial cake thickness at $1 \mathrm{~cm}$, in order to have a thin insulating 
layer during electro-osmosis: high cake thickness, indeed, leads to low currents due to strong resistance. The pressure was fixed at 3 bar: this value, according to literature, is sufficient to maintain the contact between sludge and electrodes. The pressure by itself is not sufficient to remove completely the water. Therefore, the use of an electric field is necessary to reach DS in the range of $40-45 \%$, which is the aimed value, considered the data in literature.

The electrode efficiencies may be evaluated on performances base and on corrosion resistance.

The total energy consumption $\left(\mathrm{Wh} / \mathrm{kg}_{\mathrm{H}_{2} \mathrm{O}}\right)$ assessment is computed by dividing the consumed energy by mass of water collected $(\mathrm{kg})$ during the tests. According to literature, after electro-osmosis dewatering, values of energy consumptions found for types of sludge with an initial DS value lower than $13 \%$ are usually under $400 \mathrm{Wh} / \mathrm{kg}_{\mathrm{H}_{2} \mathrm{O}}$. These results have been achieved with potentials from $10 \mathrm{~V}$ to $50 \mathrm{~V}$ and times higher than 3 hours $[6,18]$. Here, we chose to set an energy consumption threshold at $250 \mathrm{Wh} / \mathrm{kg}_{\mathrm{H}_{2} \mathrm{O}}$, since taking into account the national electrical energy efficiency equal to 0.47 [19], the total equivalent thermal energy consumption is $532 \mathrm{Wh} / \mathrm{kg}_{\mathrm{H}_{2} \mathrm{O}}$, much lower than the energy for thermal drying $\left(617-1200 \mathrm{Wh} / \mathrm{kg}_{\mathrm{H}_{2} \mathrm{O}}\right)$ [20].

About of the efficiencies of the electro-osmotic processes we observed the following results.

Ti-MMO (DSA): DSA ${ }^{\circledR}$ electrodes, provided by Industrie De Nora SpA are used as reference material in order to compare our results with those found in literature. Results of electrodewatering tests on sludge A are reported in Table 3. The $\mathrm{DS}_{\mathrm{f}}$ content increases from $20.1 \%$ to 38 $40.5 \%$, with an evident change of processing time as potential is increased: it is shorter in tests at 20 $\mathrm{V} / \mathrm{cm}$ due to a higher kinetics. It is useful to remind that time is not taken as an arbitrary parameter, but it depends on the drop rate (no more than two drops in five minutes).

As stated in Section 2, energy consumption should not exceed $250 \mathrm{Wh} / \mathrm{kg}_{\mathrm{H}_{2} \mathrm{O}}$, in order to be costeffective and energy efficient. Therefore, the test at $20 \mathrm{~V} / \mathrm{cm}$ exceeds this threshold. We can deduce that higher is the potential, higher is the total energy consumption (due to an increase in values of current density), if the result is equal in terms of $\mathrm{DS}_{\mathrm{f}}$ amount.

Figure 3 shows the most relevant results of electro-dewatering tests on sludge A and sludge B. Current density, collected water mass and rate of the dewatering with time for different applied electric field are reported. The curves of the current density show a maximum in a very short time from the electric field application time $\left(t_{\mathrm{E}}<5 \mathrm{~min}\right)$, depending on the initial DS content $\left(\mathrm{DS}_{\mathrm{i}}\right)$ of the sludge, and then abruptly decreases near zero in 20-25 minutes. The maximum indeed is at about 70 $\mathrm{mA} / \mathrm{cm}^{2}$ for sludge A and the half for sludge B, which have respectively $20.1 \%$ and $27.9 \%$ of $\mathrm{DS}_{\mathrm{i}}$ content. The dewatering begins soon after the current density maximum, after an induction time, with a rate that is the highest at maximum slope decrease point. As said before, a specific trend is observed: increasing the electric field (from $10 \mathrm{~V} / \mathrm{cm}$ to $20 \mathrm{~V} / \mathrm{cm}$ ), a minor time is spent before the dewatering stop. This kind of behaviour is confirmed by Tuan [18]: higher the potential, higher is the kinetics of the process. The dependence from the $\mathrm{DS}_{\mathrm{i}}$ content of the process efficiencies indicates a strong 
influence of the wetted percent area of the electrodes, especially in the first 15-20 min of the experiments: some coating with hydrophilic surface might increase the process yield. However, after the first period of the tests, where dewatering rate and current densities are high enough, the electric resistance is affected mainly by the dry sludge layer that develops at the anode, rather than by the entire cake itself. This is because this thin dry sludge layer that develops in contact to the anode dissipate currents by Joule effect without an effective improvement in water removal. The use of a water jacket guaranteed the thermal stability inside the cell: our tests confirmed that values of potentials lower than $20 \mathrm{~V}$ could not increase the temperature over $30^{\circ} \mathrm{C}$, so the Joule effect and water evaporation are limited.

As shown previously, the DSA does not show evident corrosion after many tests ( $>50$ hours). It is however very expensive and a cheaper material is needed. As a consequence, we tested bare stainless steel and PVD coated stainless steel to be used as anodes.

X5CrNi18-10 (AISI 304): bare stainless steel (AISI 304) was firstly investigated with the same procedures used for DSA. Anodes consisted of circular discs with five holes $(\varnothing=8.2 \mathrm{~mm})$ to let the gas overflow.

Starting from sludge $\mathrm{C}\left(\mathrm{DS}_{\mathrm{i}}=23.6 \%\right)$, we performed tests with three stainless steel discs at the usual initial conditions: $35 \mathrm{~g}$ of sludge ( $1 \mathrm{~cm}$ of thickness), 3 bar of pressure and electric field values ranging from 10, 15 and $20 \mathrm{~V} / \mathrm{cm}$. The results are shown in Table 4.

$\mathrm{DS}_{\mathrm{f}}$ amount are not as high as expected for tests at 10 and $15 \mathrm{~V} / \mathrm{cm}$. A higher potential is needed to increase $\mathrm{DS}_{\mathrm{f}}$ up to values around $37 \%$. This result is strictly related to the low maximum current density values obtained at 10 and $15 \mathrm{~V} / \mathrm{cm}$. Moreover, the corrosion of the discs is the main problem encountered during the experiments: localized corrosion was evident since the first test and the situation got worse increasing the electric field application time. This fact might be one of the causes of low dewatering.

In Figure 4 we can see that the first drop (usually corresponds to the time of maximum in a current density vs time diagram) is obtained at relative low times in every tests, as expected for a sludge with a $\mathrm{DS}_{\mathrm{i}}$ under $25 \%$. The current densities developed during the process are comparable with those of DSA anode. The electro-osmosis tests last shorter times with respect to the experiments with DSA anode, probably due to the strong corrosion of the surface.

TiN: starting from the results obtained on the stainless steel substrate, we tested two different TiN coatings ( $1 \mu \mathrm{m}$ and $3 \mu \mathrm{m}$ of thickness) at $15 \mathrm{~V} / \mathrm{cm}$. The results are shown in Table 5 .

As shown, we achieved better results in terms of $\mathrm{DS}_{\mathrm{f}}$ with respect to those found with stainless steel anode. This fact can be attributed primarily to the higher currents developed during the tests with respect to the experiments with bare stainless steel anodes: maximum current density values were $15-40 \mathrm{~mA} / \mathrm{cm}^{2}$ higher for TiN coated samples, depending on the coating thickness. Therefore, at $15 \mathrm{~V} / \mathrm{cm}$ we succeed, also with coated samples, in removing a suitable 
amount of water, like with DSA experiments, in restricted times.

However, these kinds of results are obtained only with the first tests with the virgin anodes: after 10 min of potential application, the TiN discs are completely corroded and no other experiments can be performed due to their behaviour as a resistor.

Diagrams related to the tests with TiN discs are shown in Figure 5. As expected, the maximum values of current density are achieved for the thinnest coatings, due to a reduced resistance of the ceramic layer. Moreover, the first drop is obtained later in time with a thick coating.

AlTiN: starting from a cake thickness of $3 \mathrm{~cm}$ (corresponding to $60 \mathrm{~g}$ ) of sludge $\mathrm{D}\left(\mathrm{DS}_{\mathrm{i}}=21.9 \%\right.$ ), we performed two tests by using a AlTiN coated stainless steel anode: one with the static (D-1) and one with the rotating piston (D-2) started after 7 minutes of electric field application. For both the tests, the pressure has been maintained at 3 bar and the potential at $15 \mathrm{~V}(5 \mathrm{~V} / \mathrm{cm})$. The results are shown in Table 6.

$\mathrm{DS}_{\mathrm{f}}$ are not as high as in the previous experiments, since electro-osmosis is not suitable in the case of high cake thicknesses $(3 \mathrm{~cm})$ due to the strong resistance between the electrodes. However, it seems that the $\mathrm{DS}_{\mathrm{f}}$ obtained by the rotation of the piston is slightly higher and the energy consumption is consequently lower with respect to the static experiment.

Figure 6a shows the current density vs time diagrams of tests D-1 and D-2. The shape of the curve relative to the static experiment is continue and has a maximum in $26 \mathrm{~mA} / \mathrm{cm}^{2}$, while for D-2 initially the current density slightly increases and then it raises with a discontinuous step after the starting of rotation (7 minutes).

From this preliminary analysis, it seems that the main characteristic that must be taken into account for the electro-osmosis dewatering is the sludge cake thickness. The rotation of the anode seems to be efficient in increasing the conductivity of sludge, but this phenomenon could be more pronounced with a lower initial cake thickness $(1-1.5 \mathrm{~cm})$. For low times of electric field applications, corrosion is important but not the leading parameter. However, when the coated anodes have a long processing time, it is inevitable that corrosion greatly influences sludge dewaterability.

DLC: the same dynamic tests have been performed for DLC coated anodes. By applying 3 bar and $15 \mathrm{~V}(5 \mathrm{~V} / \mathrm{cm})$ on a $3 \mathrm{~cm}$-cake, we investigated the behaviour of sludge D after starting the rotation of the piston (minute 7).

The DS results are in the range of D-2 test and energy consumption is still quite high. The main issue for low efficiency is not the kind of PVD coating used, but it mainly depends on the high cake thickness and consequent high resistivity.

Current density vs time diagrams of tests D-3 and D-4 are shown in Figure 6b. Slopes, after the start of rotation, increase of about $5 \mathrm{~mA} / \mathrm{cm}^{2}$ thanks to the increase in conductivity got by the movement of the cake surface. However, the efficiency is still too low because of the high sludge thickness. 
As stated above, the efficiency of the electro-osmosis process is strictly related to the conductivity of the sludge cake and to the electrode corrosion and damage. In fact, due to the oxygen evolution and the acidic environment on the anode, their performances worsen with time and our purpose is the investigation of their resistance with a preliminary study in the lab-scale device. In the followings we analyse the different materials.

MMO-Ti (DSA): the photograph and the SEM picture of DSA after electro-osmotic tests ( $>50$ hours) shown in Figure 7a reveal a homogeneous surface without any porosity or coloured oxidised area. The rough surface shows the presence of mixed metal oxides and corrosion seems to be inexistent.

X5CrNi18-10 (AISI 304) anode: localized corrosion is the main phenomenon occurring during electroosmosis for stainless steel anodes. The kind of corrosion is clearly identified observing the photographs reported in Figure $7 \mathrm{~b}$ : deep pits and holes on the surface are formed after short experimental times. The corrosion of the anode material may not only slow down the water removal, but also contaminate the sludge cake (the content of cadmium, copper, nickel, lead, zinc, mercury and chromium in the sludge is strictly regulated by Directive 2008/98/EC for disposal in agriculture). These results clearly underline the ineffectiveness of stainless steel (AISI 304) to be used as anode in the process of sludge electro-osmosis. The high current densities circulating during the tests, oxygen evolution and the high $\mathrm{pH}$ near the anode are detrimental for the anode service life. Stainless steel when used as anode, has no beneficial effects with respect to carbon steel, since it is strongly corroded due to the initial dissolution of the passive film induced by anodic acidity.

TiN: the aspect of TiN anodes after electro-osmosis tests at $15 \mathrm{~V} / \mathrm{cm}$ is shown in Figure $7 \mathrm{c}$. Localized corrosion is the main mechanism during these tests and it is caused by the great presence of pores in the ceramic coating on stainless steel. This fact is deleterious for the efficiency of the process since the contact between substrate and sludge environment causes a rapid dissolution of metal. A high coating thickness, with a less porous structure, might improve the corrosion resistance of the anode but, at the same time, a too much thick coating will condition the resistivity of the anodes. A compromise between these factors must be found. From the picture, it seems that the depth and the extension of the pits were slightly reduced with respect to bare stainless steel anodes, considering a similar service life and equal applied potential values.

AlTiN: looking at Figure $7 \mathrm{~d}$ we can see the morphology of the AlTiN coated anode 50 minutes of potential application $(15 \mathrm{~V})$. Pits are largely reduced in this case, thanks to the higher cake thickness and the lower current densities developed during the process. It is clear that the corrosion is one of the deleterious factors for removing water from sludge, together with the high resistivity of the cake. It is also evident that by using a virgin anode on a static piston the efficiency is lower than the corroded disc on the rotating piston: this fact seems to highlight that, for low experimental times, the higher efficiency is most influenced by an increase in conductivity of the cake rather than by a higher conductivity of the anode. For low times of electric field applications, corrosion is important but not 
the leading parameter. However, when the coated anodes have a long processing time, is inevitable that corrosion greatly influences sludge dewaterability.

DLC: in Figure 7e DLC anode after tests D-3 and D-4 at $15 \mathrm{~V}$ is shown. In this case it seems that the main phenomenon occurring during electro-osmosis tests is erosion corrosion: there is a general damage of the anode surface and localized corrosion is not evident like in the previous pictures.

Delamination of the DLC coating was probably caused also by a lower adherence on the substrate. This fact could be ascribed also for a greater presence of pores into the DLC layer with respect to other ceramic coatings.

\section{Conclusions}

The electro-dewatering of sludge seems an efficient method to increase the dry solid content of the dewatered sludge. It could offer an alternative process to the more costly thermal drying methods that are usually applied for energy production from sludge through combustion processes.

The main parameters that control electro-osmosis process were sludge cake thickness, potential value and initial DS amount. The experiments have been performed by measuring the current densities developed during the tests, the temperature at the anode inside the cell, $\mathrm{DS}_{\mathrm{f}}$ of the sludge cake and computing the energy consumption. By using the lab-scale device, we set electric fields values at $10 \mathrm{~V} / \mathrm{cm}, 15 \mathrm{~V} / \mathrm{cm}$ and $20 \mathrm{~V} / \mathrm{cm}$ with a pressure of $300 \mathrm{kPa}$. The main results are the following:

- DS reached final values up to $40 \%$.

- Tests at 10-15 V/cm have shown the best compromise between $\mathrm{DS}_{\mathrm{f}}$ and energy consumption.

- Electro-dewatering is energetically convenient if compared to thermal drying.

- Electro-dewatering may have a great potential for practical applications in most cases. For example, if sludge is disposed of at $\mathbf{4 0 \%}$ dry matter instead of $\mathbf{2 5 \%}$, the total mass to be disposed (and the inherent costs) will be reduced by a factor of 1.6 and the lower disposal costs widely compensate the cost of energy for the electro-osmotic dewatering. Furthermore, if sludge is incinerated, electro-dewatered sludge at $40 \%$ DS can selfsustain combustion at $850^{\circ} \mathrm{C}$, avoiding a thermal drying step.

The greatest challenge is to keep an advantageous compromise between the high costs for production and maintenance of corrosion and wear resistant electrodes and the overall cost of the equipment. This article refers to the first steps of the investigation that, taking into account already known chemical physical drawbacks (anodic dissolution of iron based materials), aims to achieve a methodology for determine the issue.

Efficiency and corrosion are useful parameters for the assessment of the process and of the electrode materials. From the efficiency point of view, the limit of $250 \mathrm{Wh} / \mathrm{kg}_{\mathrm{H}_{2} \mathrm{O}}$, that is much lower than values reported in the literature, was respected only by the TiN coated stainless steel electrode. The 
ranking with an electric field of $15 \mathrm{~V} / \mathrm{cm}$, of the examined materials is: $\operatorname{TiN}\left(\mathrm{DS}_{\mathrm{f}} \approx 39,0 \%\right)>\mathrm{DSA}$ $\left(\mathrm{DS}_{\mathrm{f}} \approx 39.9 \%\right)>$ DLC-rot $\left(\mathrm{DS}_{\mathrm{f}} \approx 27.9 \%\right)>\operatorname{AlTiN}-\operatorname{rot}\left(\mathrm{DS}_{\mathrm{f}}=28.0 \%\right)>\operatorname{AlTiN}\left(\mathrm{DS}_{\mathrm{f}}=25.7 \%\right)>$ AISI 304 $\left(\mathrm{DS}_{\mathrm{f}} \approx 29.4 \%\right)$.

Energy efficiency data are shown in Figure 8 together with the DS percentage at the end of tests. It must be observed that the results strongly depend on sludge characteristics and cake thickness.

From the corrosion point of view, stainless steel electrodes are the most corroded ones among those investigated: a large area dense of localized corrosion is evident on the surface. The DSA electrodes are the best performing as for corrosion damage: they do not show any evident surface degradation. The ceramic-coated stainless steel electrodes exhibit intermediate corrosion degradation. This preliminary investigation has pointed out the characteristics of some materials for the electroosmotic tests and it has delineated the methodology of the research. The work indicates that research should focus on a material constituted by a conductive metal coated by a conductive film resistant to wear and corrosion, in order to simulate the performances of commercial DSA electrode. With this aim, polymeric or ceramic coatings with graphene dispersion are currently under investigation.

\section{Acknowledgements}

The authors wish to thank Metropolitana Milanese Spa for supplying sludge samples and Industrie De Nora Spa for providing DSA electrode. This work has received funding from the Project SLUDGEtreat, co-funded by the European Commission within the FP7 (2007-2013) Marie Curie Actions- Industry- Academia Partnerships and Pathways - IAPP, GA n. 611593, and from the LIFE14 project no. ENV/IT/000039 "ELECTRO-SLUDGE", with the contribution of the LIFE Programme of the European Union.

\section{References}

[1] Yoshida, H. Practical aspects of dewatering enhanced by electro-osmosis. Drying Technology 1993, 11(4), 787-814.

[2] Barton, W. A.; Miller, S. A.; Veal, C. J. The electrodewatering of sewage sludges. Drying Technology 1999, 17(3), 497-522.

[3] Gingerich, I.; Neufeld, R. D.; \& Thomas, T. A. Electroosmotically enhanced sludge pressure filtration. Water Environmental Research 1999, 71(3), 267-276.

[4] Mahmoud, A.; Hoadley, A. F. A; Conrardy J. B.; Olivier, J.; Vaxelaire, J. Influence of the operating parameters on dryness level and energy saving during wastewater sludge electrodewatering. Water Research 2016, 103, 109-123.

[5] Larue, O; Wakeman, R. J.; Tarleton, E. S.; Vorobiev, E. Pressure electroosmotic dewatering with continuous removal of electrolysis products. Chemical Engineering Science 2006, 61, 4732-474.

[6] Mahmoud, A.; Olivier, J.; Vaxelaire, J.; Hoadley, A. F. A. Electro-dewatering of wastewater 
sludge: influence of the operating conditions and their interactions effects. Water Research 2011, 45(9), 2795-2810.

[7] Olivier, J.; Conrardy, J. B.; Mahmoud, A.; Vaxelaire, J. Electro-dewatering of wastewater sludge: an investigation of the relationship between filtrate flow rate and electric current. Water Research 2015, 82, 66-77.

[8] Citeau, M.; Larue, O.; Vorobiev, E. Influence of salt, $\mathrm{pH}$ and polyelectrolyte on the pressure electro-dewatering of sewage sludge. Water Research 2011, 45(6), 2167-2180.

[9] Yuan, C.; Weng, C. Sludge dewatering by electrokinetic technique: Effect of processing time and potential gradient. Advances in Environmental Research 2003, 7(3), 727-732.

[10] Tuan, P.; Sillanpää, M. Migration of ions and organic matter during electro-dewatering of anaerobic sludge. Journal of Hazardous Materials 2010, 173(1-3), 54-61.

[11] Tuan, P.; Jurate, V.; Mika, S. Electro-dewatering of sludge under pressure and nonpressure conditions. Environmental Technology 2008, 29(10), 1075-1084.

[12] Citeau, M.; Loginov, M.; Vorobiev, E. Improvement of sludge electrodewatering by anode flushing. Drying technology 2016, 34(3), 307-317.

[13] Raats, M. Full scale electrokinetic dewatering of waste sludge. Colloids and Surfaces. A Physicochemical and Engineering Aspects 2002, 210(2-3), 231-241.

[14] Saveyn, H.; Van der Meeren, P.; Pauwels, G.; Timmerman, R. Bench- and pilot-scale sludge electrodewatering in a diaphragm filter press. Water Science \& Technology 2006, 54(9), 53-60.

[15] Mahmoud, A.; Olivier, J.; Vaxelaire, J.; Hoadley, A. F. A. Electrical field: a historical review of its application and contributions in wastewater sludge. Water Research 2010, 44, 2381-2407.

[16] APHA, AWWA, WEF. Standard Methods for the Examination of Water and Wastewater, $22^{\text {nd }}$ Edit., Rice, E.W., Baird, R.B., Eaton, A.D., Clesceri, L.S., Eds., 2012.

[17] Conrardy, J. B.; Vaxelaire, J.; Olivier, J. Electro-dewatering of activated sludge: electrical resistance analysis. Water Research 2016, 100, 194-200.

[18] Tuan, P. Sewage sludge electro-dewatering, Acta Universitatis Lappeenrantaensis. Thesis, Mikkeli University Consortium, Finland, 2011.

[19] Caputo, A; Sarti, C. Fattori di emissione atmosferica di $\mathrm{CO}_{2}$ e sviluppo delle fonti rinnovabili nel settore elettrico, Rapporto ISPRA 212/2015, 2015. http://www.isprambiente.gov.it/, (visited on October 17th, 2016)

[20] Olivier, J.; Mahmoud, A.; Vaxelaire, J.; Conrardy, J. B.; Citeau, M.; Vorobiev, E. Electrodewatering of anaerobically digested and activated sludges: an energy aspect analysis. Drying technology 2014, 32(9), 1091-1103. 


\section{Figures}

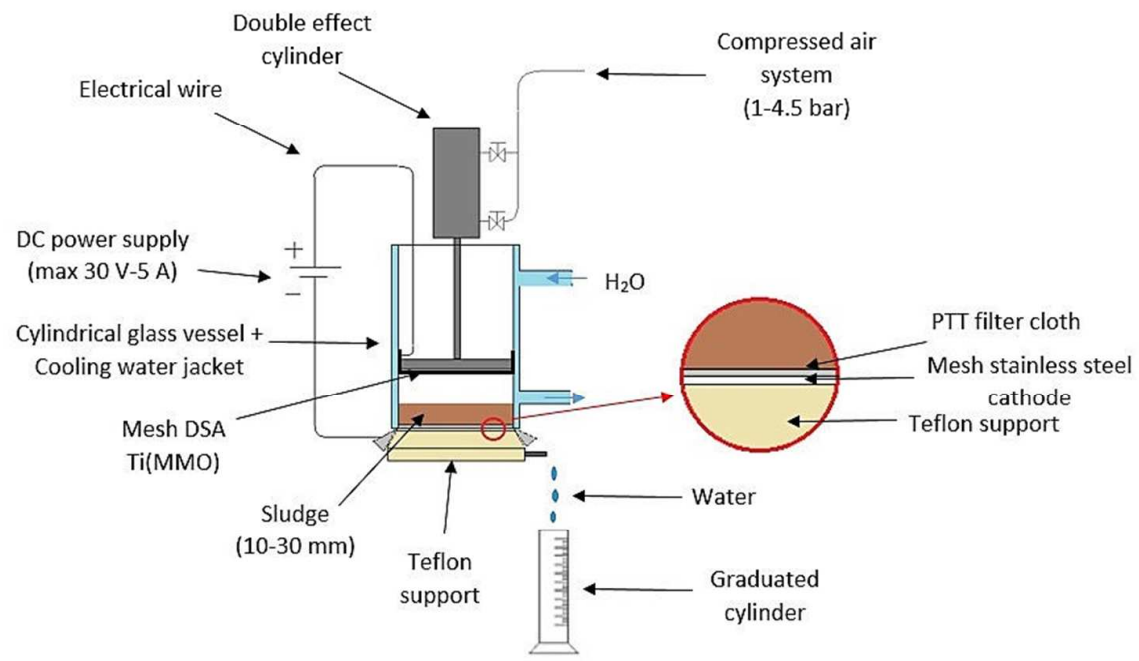

Figure 1. Lab-scale apparatus for sludge electro-dewatering tests.

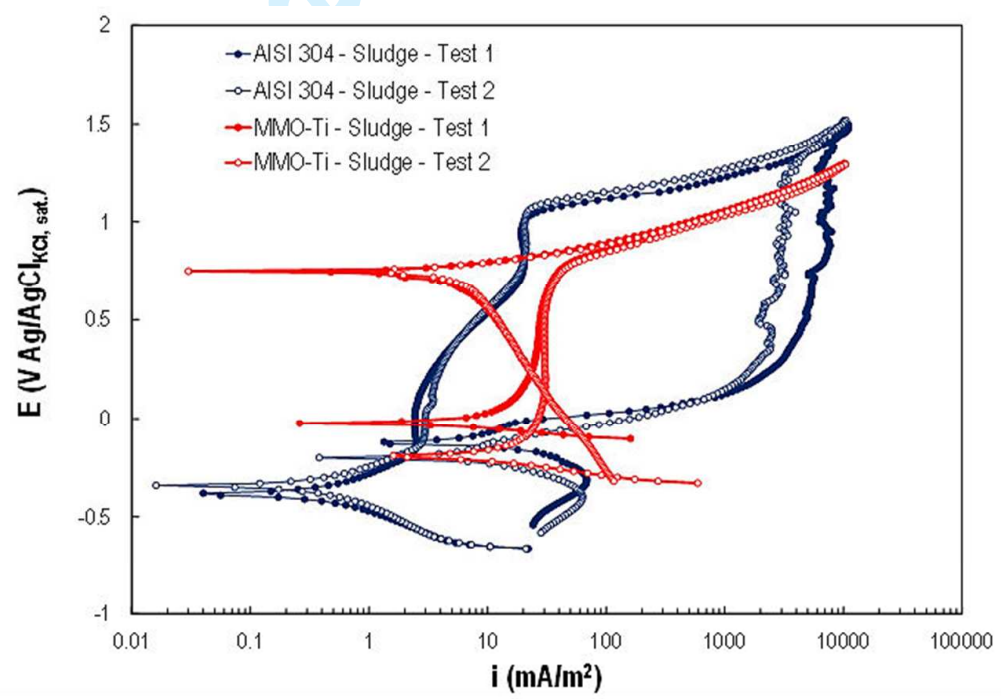

Figure 2. Cyclic polarization curves on AISI 304 and DSA electrodes. 
a

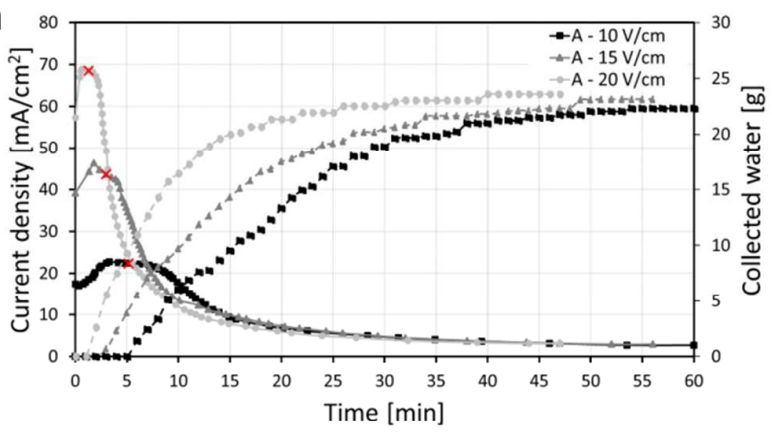

\section{C}

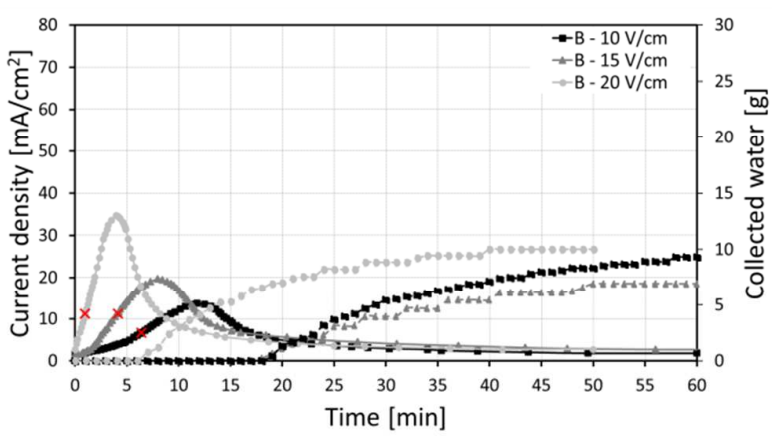

b

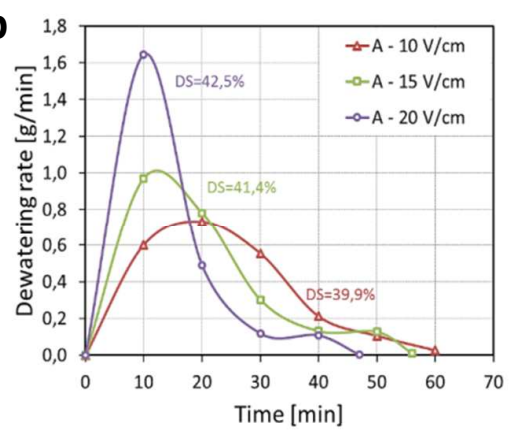

d

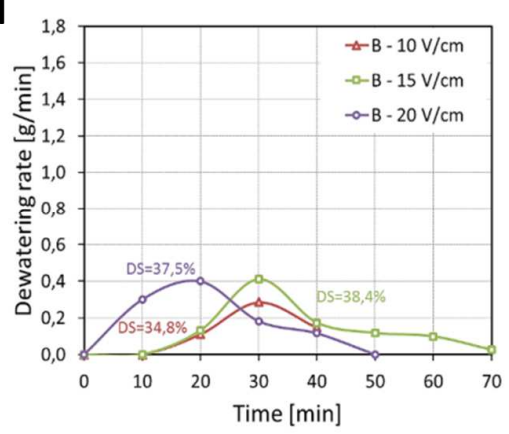

Figure 3. Diagrams for electro-dewatering test with DSA on sludge $A\left(\mathrm{DS}_{\mathrm{i}}=20.1 \%\right)$ and $\mathrm{B}$ $\left(\mathrm{DS}_{\mathrm{i}}=27.9 \%\right)$ at 10,15 and $20 \mathrm{~V} / \mathrm{cm}$ showing: (a, c) Current density (solid lines) and collected water mass (dotted lines) vs time; (b, d) dewatering rate vs time.

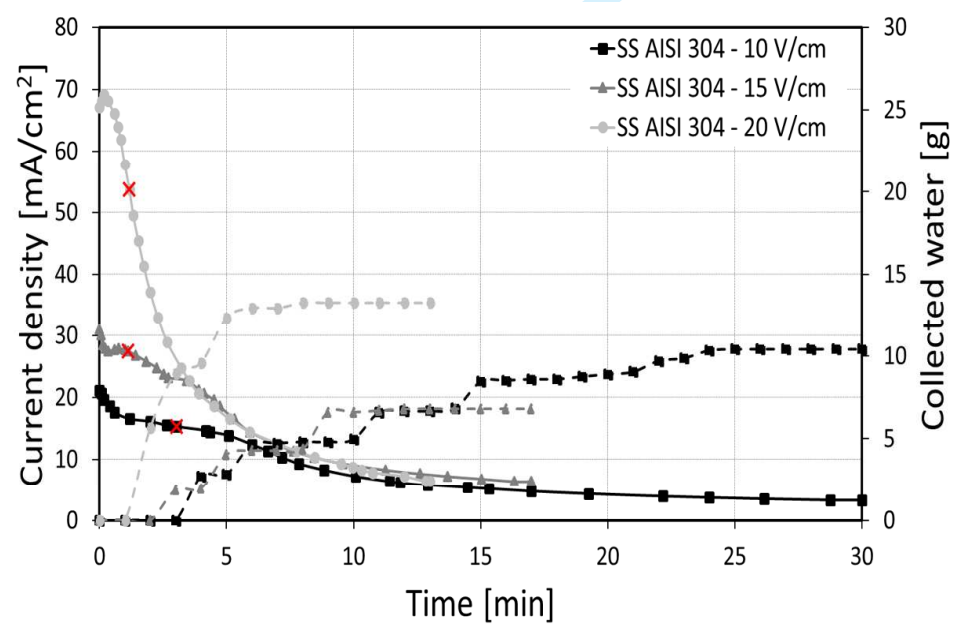

Figure 4. Diagram of electro-dewatering tests with sludge $\mathrm{C}\left(\mathrm{DS}_{\mathrm{i}}=23.6 \%\right)$ with stainless steel (AISI 304) anodes: current density (solid lines) and collected water mass (dotted lines) vs time. Best results. 
1

2

3

4

5

12

13

14

15

16

17

18

19

20

21

22

23

24

25

26

27

28

29

30

31

32

33

34

35

36

37

38

39

40

41

42

43

44

45

46

47

48

49

50

51

52

53

54

55

56

57

58

59

60

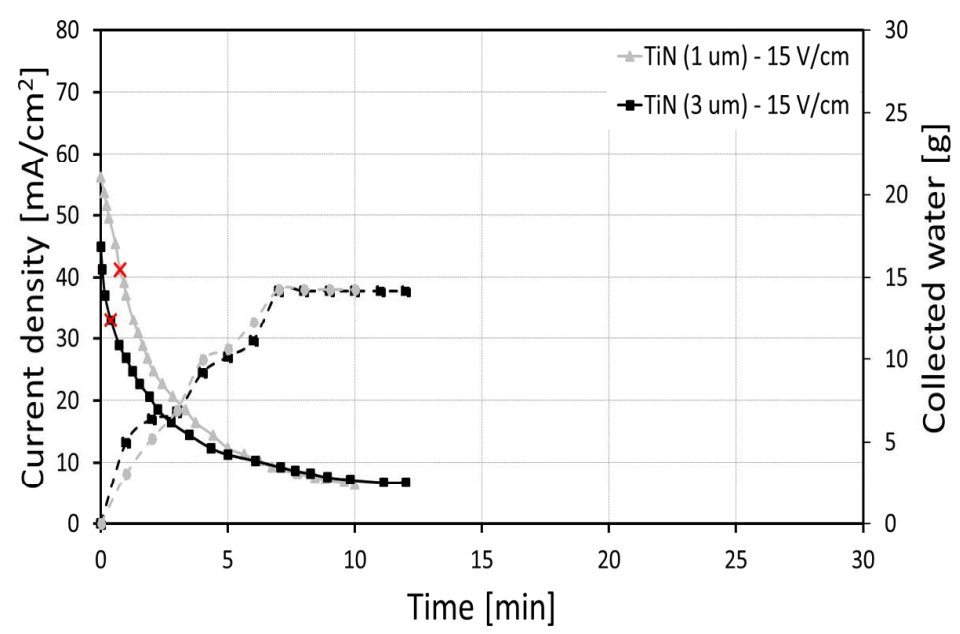

Figure 5. Diagram of electro-dewatering tests with sludge $\mathrm{C}\left(\mathrm{DS}_{\mathrm{i}}=23.6 \%\right)$ with TiN coated anodes $(1 \mu \mathrm{m}$ and $3 \mu \mathrm{m})$ at $15 \mathrm{~V} / \mathrm{cm}$ : current density (solid lines) and collected water mass (dotted lines) vs time.
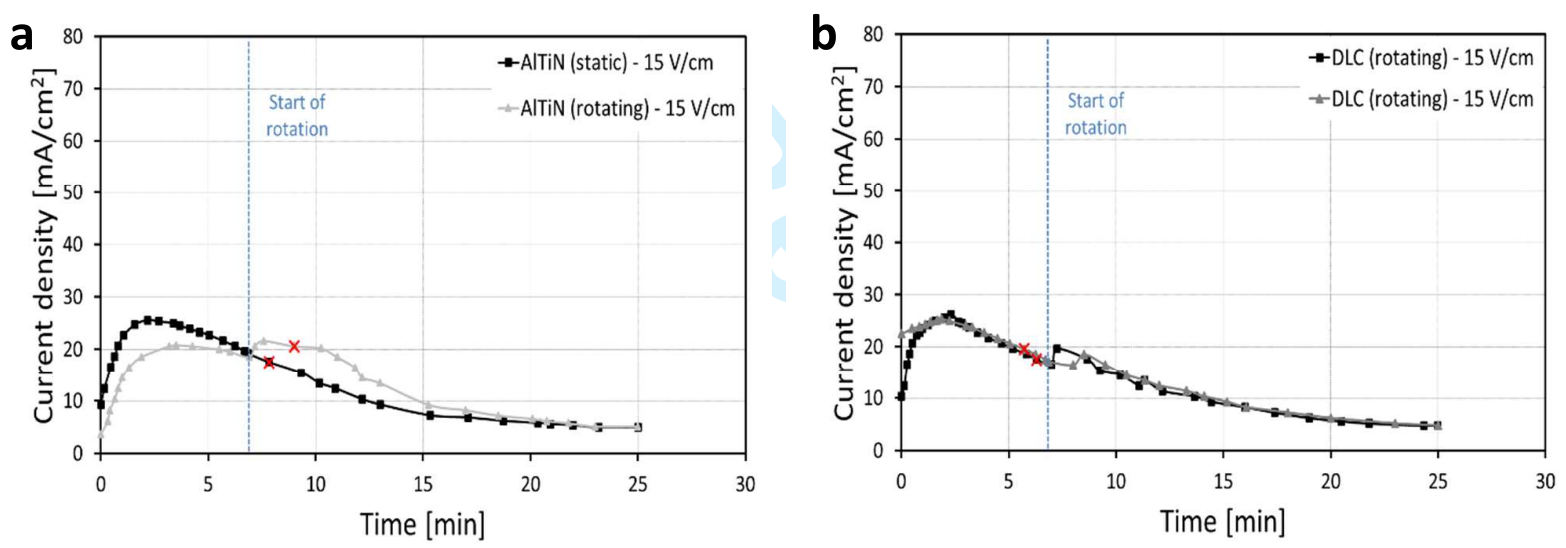

Figure 6. Diagrams of electro-dewatering tests with sludge $\mathrm{D}\left(\mathrm{DS}_{\mathrm{i}}=21.9 \%\right)$ with (a) AlTiN coated anode (static and rotating piston) and (b) DLC coated anode (rotating piston) at $15 \mathrm{~V} / \mathrm{cm}$ : current density vs time. 
a
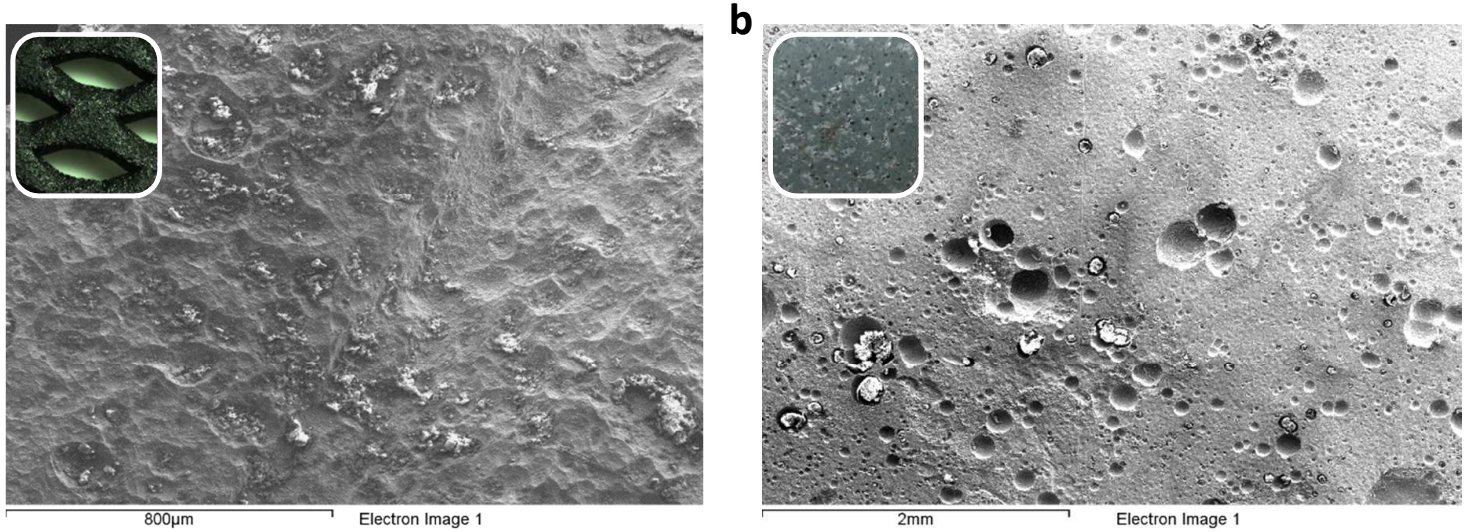

C

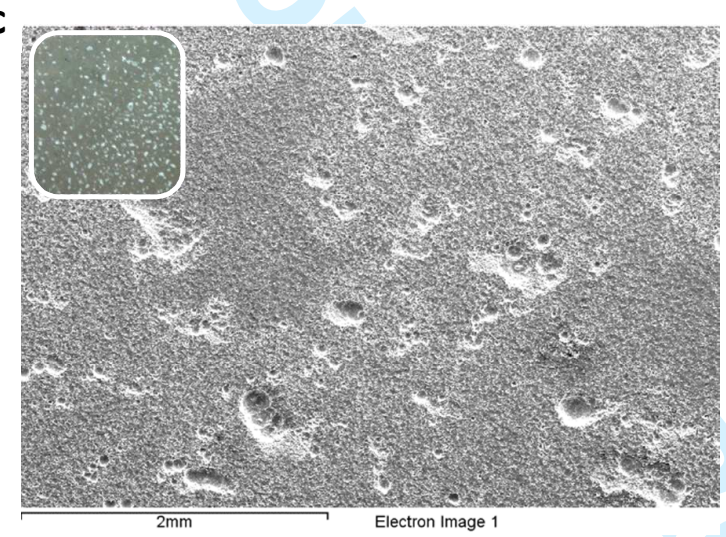

d

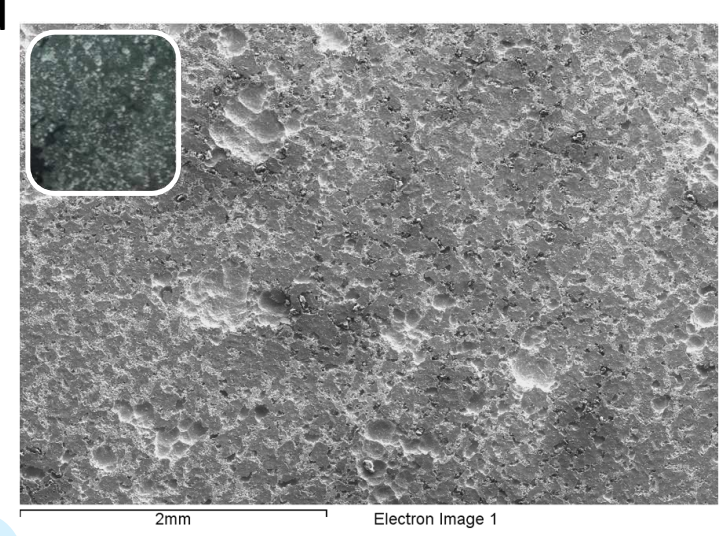

e

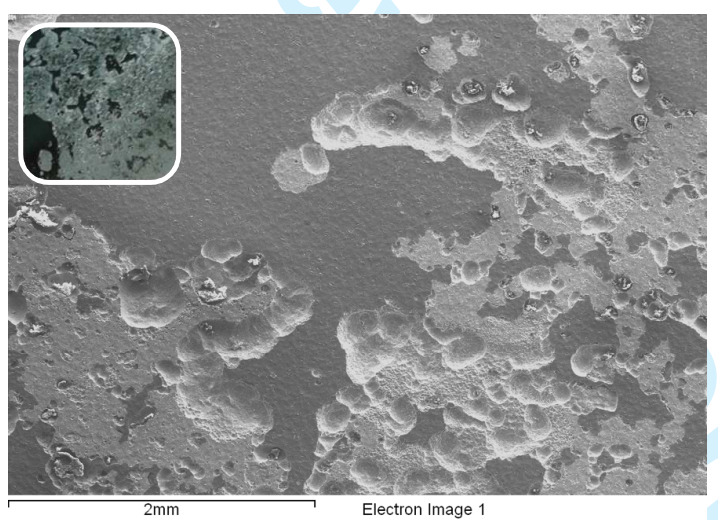

Figure 7. Photographs and SEM images of electrode materials after electro-osmosis test at $15 \mathrm{~V} / \mathrm{cm}$ :

(a) DSA ( $\mathbf{t}_{\text {TOT }}>\mathbf{5 0}$ hours), (b) stainless steel AISI 304 ( $\left.\mathbf{t}_{\text {TOT }} \approx \mathbf{3 0} \mathbf{~ m i n}\right)$, (c) TiN coated anode

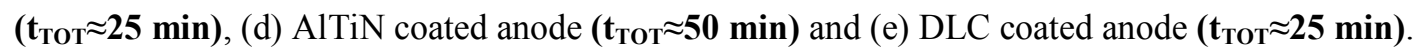


1

2

3

4

5

6

7

8

9

10

11

12

13

14

15

16

17

18

19

20

21

22

23

24

25

26

27

28

29

30

31

32

33

34

35

36

37

38

39

40

41

42

43

44

45

46

47

48

49

50

51

52

53

54

55

56

57

58

59

60

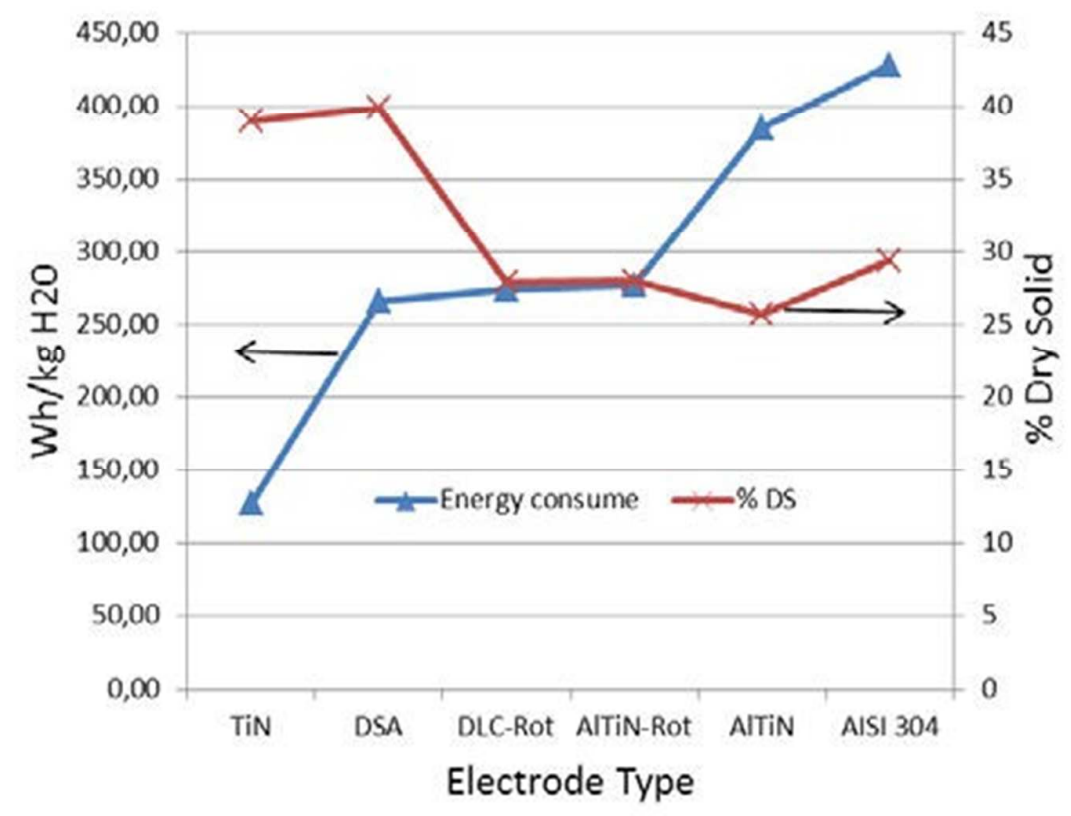

Figure 8. Specific energy consumption and $\mathrm{DS}_{\mathrm{f}}$ content for anodes used in the tests $(\mathrm{E}=15 \mathrm{~V} / \mathrm{cm})$. 


\section{Tables}

Table 1. Sludge samples characteristics (DS = dry solid; VS = volatile solid).

\begin{tabular}{cccccc}
\hline Sludge & Mech. dewatering & $\mathrm{DS}_{\mathrm{i}}[\%]$ & $\mathrm{VS} / \mathrm{DS}[\%]$ & $\mathrm{pH}$ & $\begin{array}{c}\text { Conductivity } \\
{[\mu \mathrm{S} / \mathrm{cm}]}\end{array}$ \\
\hline A & Bucher press & 20.1 & 70.1 & 5.5 & N.A. \\
B & Filter press & 27.9 & 72.7 & 6.3 & N.A. \\
C & Filter press & 23.6 & 73.2 & 6.0 & 1132 \\
D & Filter press & 21.9 & 75.9 & 5.5 & 1277 \\
\hline
\end{tabular}

Table 2. PVD Coatings on stainless steel (AISI 304) anodes.

\begin{tabular}{cccc}
\hline & TiN & AlTiN & DLC \\
\hline Layer Thickness $[\mu \mathrm{m}]$ & $1-4$ & $2-4$ & $2-4$ \\
Hardness $[\mathrm{HV}]$ & 2500 & 3200 & 2700 \\
Friction coefficient $(*)$ & 0.4 & 0.5 & 0.1 \\
Oxidation Temp. [ $\left.{ }^{*} \mathrm{C}\right]$ & 450 & 1100 & 400 \\
Colour & Golden & Black violet & $\begin{array}{c}\text { Black } \\
\text { anthracite }\end{array}$ \\
\hline
\end{tabular}

$\left(^{*}\right)$ Tested against hardened steel at $25^{\circ} \mathrm{C}$ and $85 \%$ humidity.

Table 3. Electro-osmosis of sludge A $\left(\mathrm{DS}_{\mathrm{i}}=20.1 \%\right)$ with DSA.

\begin{tabular}{ccccc}
\hline $\begin{array}{c}\text { Sludge and value } \\
\text { identity }\end{array}$ & $\mathrm{E}[\mathrm{V} / \mathrm{cm}]$ & $\begin{array}{c}\mathrm{t}_{\mathrm{TOT}} \\
{[\mathrm{min}]}\end{array}$ & $\begin{array}{c}\text { Tot. energy } \\
\text { consumption } \\
{\left[\mathrm{Wh} / \mathrm{kg}_{\mathrm{H} 2 \mathrm{O}}\right]}\end{array}$ & $\mathrm{DS}_{\mathrm{f}}[\%]$ \\
\hline $\mathrm{AM}$ & 10 & $65-105$ & 168.7 & 38.9 \\
$\mathrm{AM}$ & 15 & $55-61$ & 266.3 & 39.9 \\
$\mathrm{AM}$ & 20 & $45-52$ & 343.9 & 40.5 \\
\hline
\end{tabular}

Table 4. Electro-osmosis results of sludge $\mathrm{C}\left(\mathrm{DS}_{\mathrm{i}}=23.6 \%\right)$ with stainless steel (AISI 304$)$ anode.

\begin{tabular}{ccccc}
\hline $\begin{array}{c}\text { Sludge and value } \\
\text { identity }\end{array}$ & $\mathrm{E}[\mathrm{V} / \mathrm{cm}]$ & $\begin{array}{c}\mathrm{t}_{\mathrm{TOT}} \\
{[\mathrm{min}]}\end{array}$ & $\begin{array}{c}\text { Tot. energy } \\
\text { consumption } \\
{\left[\mathrm{Wh} / \mathrm{kg}_{\mathrm{H} 2 \mathrm{O}}\right]}\end{array}$ & $\mathrm{DS}_{\mathrm{f}}[\%]$ \\
\hline $\mathrm{CM} 1$ & 10 & $30-35$ & 495.4 & 27.1 \\
$\mathrm{CM} 2$ & 15 & $22-25$ & 428.8 & 29.4 \\
$\mathrm{CM} 3$ & 20 & $18-23$ & 287.6 & 37.1 \\
\hline \multicolumn{4}{c}{ *Each value is the medium (M) value of 3 tests at least. }
\end{tabular}


Table 5. Electro-osmosis results of sludge $\mathrm{C}\left(\mathrm{DS}_{\mathrm{i}}=23.6 \%\right)$ with $\mathrm{TiN}$ coated anode.

\begin{tabular}{ccccc}
\hline $\begin{array}{c}\text { Sludge and value } \\
\text { identity }\end{array}$ & $\mathrm{E}[\mathrm{V} / \mathrm{cm}]$ & $\begin{array}{c}\mathrm{t}_{\mathrm{TOT}} \\
{[\mathrm{min}]}\end{array}$ & $\begin{array}{c}\text { Tot. energy } \\
\text { consumption } \\
{\left[\mathrm{Wh} / \mathrm{kg}_{\mathrm{H} 2 \mathrm{O}}\right]}\end{array}$ & $\mathrm{DS}_{\mathrm{f}}[\%]$ \\
\hline $\mathrm{C}-10(1 \mu \mathrm{m})$ & 15 & 17 & 119.2 & 39.7 \\
$\mathrm{C}-11(3 \mu \mathrm{m})$ & 15 & 18 & 136.9 & 38.8 \\
\hline
\end{tabular}

Table 6. Electro-osmosis results of sludge $\mathrm{D}\left(\mathrm{DS}_{\mathrm{i}}=21.9 \%\right)$ with AlTiN coated anode.

\begin{tabular}{ccccc}
\hline $\begin{array}{c}\text { Sludge and value } \\
\text { identity }\end{array}$ & $\mathrm{E}[\mathrm{V} / \mathrm{cm}]$ & $\begin{array}{c}\mathrm{t}_{\mathrm{TOT}} \\
{[\mathrm{min}]}\end{array}$ & $\begin{array}{c}\text { Tot. energy } \\
\text { consumption } \\
{\left[\mathrm{Wh} / \mathrm{kg}_{\mathrm{H} 2 \mathrm{O}}\right]}\end{array}$ & $\mathrm{DS}_{\mathrm{f}}[\%]$ \\
\hline D-1 (static) & 15 & 30 & 385.1 & 25.7 \\
D-2 (rotating) & 15 & 30 & 277.3 & 28.0 \\
\hline
\end{tabular}

Table 7. Electro-osmosis results of D sludge $\left(\mathrm{DS}_{\mathrm{i}}=21.9 \%\right)$ with DLC coated anode.

\begin{tabular}{ccccc}
\hline $\begin{array}{c}\text { Sludge and value } \\
\text { identity }\end{array}$ & $\mathrm{E}[\mathrm{V} / \mathrm{cm}]$ & $\begin{array}{c}\mathrm{t}_{\mathrm{TOT}} \\
{[\mathrm{min}]}\end{array}$ & $\begin{array}{c}\text { Tot. energy } \\
\text { consumption } \\
{\left[\mathrm{Wh} / \mathrm{kg}_{\mathrm{H} 2 \mathrm{O}}\right]}\end{array}$ & $\mathrm{DS}_{\mathrm{f}}[\%]$ \\
\hline D-3 (rotating) & 15 & 30 & 253.9 & 28.3 \\
D-4 (rotating) & 15 & 30 & 296.0 & 27.5 \\
\hline
\end{tabular}

32

33

34

35

36

37

38

39

40

41

42

43

44

45

46

47

48

49

50

51

52

53

54

55

56 
1.Some more literature review could have been better, and also most of the references are little older. $\mathrm{Ti}$ improve the archival value of the article please add some latest references from last 4-5 years.

[4] Mahmoud, A.; Hoadley, A. F. A; Conrardy J. B.; Olivier, J.; Vaxelaire, J. Influence of the operating parameters on dryness level and energy saving during wastewater sludge electro-dewatering. Water Research 2016, 103, 109-123.

[5] Larue, O; Wakeman, R. J.; Tarleton, E. S.; Vorobiev, E. Pressure electroosmotic dewatering with continuous removal of electrolysis products. Chemical Engineering Science 2006, 61, 4732-474.

[6] Mahmoud, A.; Olivier, J.; Vaxelaire, J.; Hoadley, A. F. A. Electro-dewatering of wastewater sludge: influence of the operating conditions and their interactions effects. Water Research 2011, 45(9), 27952810.

[7] Olivier, J.; Conrardy, J. B.; Mahmoud, A.; Vaxelaire, J. Electro-dewatering of wastewater sludge: an investigation of the relationship between filtrate flow rate and electric current. Water Research 2015, 82, 66-77.

[12] Citeau, M.; Loginov, M.; Vorobiev, E. Improvement of sludge electrodewatering by anode flushing. Drying technology 2016, 34(3), 307-317.

[15] Mahmoud, A.; Olivier, J.; Vaxelaire, J.; Hoadley, A. F. A. Electrical field: a historical review of its application and contributions in wastewater sludge. Water Research 2010, 44, 2381-2407.

[17] Conrardy, J. B.; Vaxelaire, J.; Olivier, J. Electro-dewatering of activated sludge: electrical resistance analysis. Water Research 2016, 100, 194-200.

2.What is the criteria for choosing the parameters like sample thickness, Pressure, DC power, rotation of the piston, time for the test etc. please substantiate this.

We have added the following part:

We evaluated the above mentioned parameters on the basis of the following assumptions:

-At low electric field values, the increase of processing pressure (up to $600 \mathrm{kPa}$ ) has a strong effect on the dewatering process and leads to the enhancement of the kinetics. We choose 3 bar of pressure as an intermediate value of those studied in the previous works [4].

-The amount of initial DS (and consequently cake thickness) affects the electrical resistance of the cake especially at the first stages of the electro-dewatering process [17]. In order to avoid a strong increase of the electrical resistance, the cake thickness value was fixed at $1 \mathrm{~cm}$ for static experiments.

-The temperature at the anode increases with the applied potential due to ohmic heating. Potentials higher than $50 \mathrm{~V}$ could increase anode temperature over $90^{\circ} \mathrm{C}[6]$, with deleterious effect on the electrode's materials. We choose to keep electric field values in the range 10-15-20 V.

- The aim of the dynamic piston is the homogenisation of the dryness of the sludge cake and the neutralization of the $\mathrm{pH}$ gradient developed with electrodes reactions. A low speed $(10 \mathrm{rpm})$ was sufficient for our objectives.

\section{How economic are these DSA electrodes when compared with available electrodes?}

Added in the text at pag. 5 .

\section{Corrosion tests could have been better explained, may be corrosion rates for different electrodes may be presented.}

The service life of each electrode has been introduced in Figure 7.

Potentiodynamic tests on PVD coated electrodes would have been useless due to the high presence of pores in the coatings. The results would have been affected by the current exchanged directly from the stainless steel substrate.

URL: http://mc.manuscriptcentral.com/Immp Email: mamp@matmod.com 
5. SEM images could have been better and please mention the morphological differences in the electrodes

Morphological differences have been introduced in the text.

6. How did the authors arrive at the decision that DLC electrodes suffered erosion corrosion. there is no marked difference seen on the SEM image (fig 7e)

The SEM image and the photographs (not reported here) are different from the previous cases. The adhesion of DLC layer is scarce and delamination due to the rotation of the piston is predominant over the localized corrosion.

7. This section needs a thorough revamp and highlight the best outcomes of this research work.

The main results obtained with our work have been highlighted in this Section. 